\title{
High-dose-rate brachytherapy in treatment of non-melanoma skin cancer of head and neck region: preliminary results of a prospective single institution study
}

\author{
Bita Kalaghchi, MD', Ebrahim Esmati, MD², Reza Ghalehtaki, MD³, Marzieh Gomar, MD³, Ramin Jaberi, PhD², \\ Soraya Gholami, MSc², Somayyeh Babaloui, PhD ${ }^{4}$, Mansoureh Nabavi, MSc², Sarvazad Sotoudeh, MD³, \\ Nezhat Khanjani, MD5, Ali Kazemian, MD², Farnaz Amouzegar-Hashemi, MD², Mahdi Aghili, MD², Marzieh Lashkari, MD² \\ 'Cancer Research Center, Cancer Institute, Tehran University of Medical Sciences, Tehran, ${ }^{2}$ Radiation Oncology Research Center (RORC), \\ Cancer Institute, Tehran University of Medical Sciences, Tehran, ${ }^{3}$ Department of Radiation Oncology, Cancer Institute, Tehran University \\ of Medical Sciences, Tehran, ${ }^{4}$ Department of Medical Physics and Biomedical Engineering, Tehran University of Medical Sciences, Tehran, \\ ${ }^{5}$ Department of Radiation Oncology, Namazi Hospital, Shiraz University of Medical Sciences, Shiraz, Iran
}

\begin{abstract}
Purpose: Skin cancers are the most common human malignancy with increasing incidence. Currently, surgery is standard of care treatment for non-melanoma skin cancers. However, brachytherapy is a growing modality in the management of skin cancers. Therefore, we aimed to assess the outcome of patients with non-melanoma skin cancers treated by high-dose-rate (HDR) brachytherapy with surface mold technique.

Material and methods: In this prospective study, we recruited patients with basal cell carcinoma (BCC) and squamous cell carcinoma (SCC) of the skin who were candidates for definitive or adjuvant brachytherapy during 2013-2014. Alginate was used for making the individualized surface molds for each patient. Patients were treated with afterloading radionuclide HDR brachytherapy machine, with a total dose of 30-52 Gy in 10-13 fractions. Participants were followed for 2 years for radiation toxicity, cosmetic results, and local failures.

Results: A total of 60 patients (66.7\% male; median age, 71 years) were included, of which $42(70.0 \%)$ underwent definitive radiotherapy. Seventy-five percent of lesions were BCC. The mean total dose was $39.6 \pm 5.4 \mathrm{~Gy}$. Of patients in definitive group, $40 / 42$ (95.2\%) experienced complete clinical response after 3 months. The recurrence rate was $2 / 18$ $(11.11 \%)$ and $1 / 42(2.38 \%)$ in adjuvant and definitive groups, respectively. The percentage of grade 3-4 acute (3-month post-treatment) and late toxicities (2 years post-treatment) was $6.7 \%$ and $0 \%$, respectively. The cosmetic results were good/excellent in $96.2 \%$ of patients after 2 years of follow-up.

Conclusions: With appropriate patient selection and choosing as lowest dose per fraction as possible, HDR brachytherapy with customized surface molds yields good oncological and cosmetic results for the treatment of localized skin BCC and SCC.

Key words: brachytherapy, mold, skin neoplasms, toxicity.

\section{Purpose}

The prevalence of skin cancer has been growing both worldwide and in Iran [1]. This trend in our country has been attributed to increased incidence of the histologic type of squamous cell carcinoma (SCC) [2]. The majority of skin malignancies are non-melanoma skin cancers (NMSC), including more than $95 \%$ of cases. Basal cell carcinoma (BCC) is the most common subtype, diagnosed in $75-80 \%$ of NMSCs, followed by SCC, comprising the majority of the remaining cases [3]. Various modalities have been proposed for the treatment of NMSC based on its stage, location, histologic type, and preferences of the dermatologists and technical availabilities of each center. These include cryotherapy, surgical excision, laser therapy, topical chemotherapy, photodynamic therapy, and radiotherapy. The surgical removal is commonly preferred method for most lesions due to its low recurrence rates, 
estimated at 5\% $[4,5,6]$. The Mohs' micrographic surgery (MMS) is the surgical technique of choice to achieve the oncological cure, preserve function, and restore cosmesis [7]. However, radiotherapy is appropriate in patients in whom surgery may produce esthetic defects, or in those with comorbidities who are unable to undergo an invasive intervention. Additionally, it is indicated as an adjuvant treatment after surgery in cases of close or positive margins. The radiation therapy is as effective as surgical techniques other than MMS.

Various radiotherapy techniques have been developed to treat skin cancer such as superficial orthovoltage X-ray, electron beam, megavoltage photons, low-dose- or high-dose-rate brachytherapy, and the newly emerging electronic brachytherapy [8]. Orthovoltage X-rays, despite being efficient for delivering high doses to skin surface, are not accessible in most radiation therapy centers, particularly in middle-income countries, due to their limited clinical coverage and cost-effectiveness. Electron beam therapy is time-consuming due to individualized beam shaping and has dosimetric challenges in treating small fields [9].

Brachytherapy has been used for the treatment of malignancies since Curie and Becquerel discovered radium, and it was first applied for skin cancer treatment in 1899 [10]. Direct contact therapy was the technique of choice in the first few decades with a 10-year control rate of 73.8\% [11]. By the mid-1940s, brachytherapy lost its popularity in the treatment of skin lesions [12], until the introduction of remote afterload machines in the 1960s [13]. One of the techniques used in modern brachytherapy is placing the radioactive sources on the body surface. To do so, custom molds are created from the surface of the lesion's location. Then, catheters are implanted into the molds for afterloading of the radioactive isotopes [14].

Among the non-surgical treatments of skin cancers, there is a scarcity of data on the efficacy and outcome of high-dose-rate brachytherapy (HDR-BT) with surface molds on Iranian population, where MMS is not widely available. Also, the global experience is growing and needs further works. Accordingly, we aimed to carry out a prospective observational study on the oncological and cosmetic outcomes as well as toxicity profiles of HDR-BT with surface molds on patients with NMSC.

\section{Material and methods}

\section{Patient characteristics}

In this prospective study, all patients with pathologically proven NMSC, referring to the Cancer Institute of Imam Khomeini Hospital from September 2013 to August 2014 for definitive or adjuvant treatment with HDR-BT were included. The patients underwent clinical examination with fully exposed skin and imaging studies as indicated to rule out nodal/visceral metastasis. Indications of brachytherapy in these patients were: 1 . definitive treatment of T1-2 N0 tumors; 2 . adjuvant treatment after surgical excision with a positive margin or residual (microscopic or gross) disease. Patients were excluded from the study if their lesions were thicker than $1 \mathrm{~cm}$, extended to the periosteum or brain parenchyma, or metastasized to the lymphatics or distant viscera. Therefore, thorough explanations were given to the eligible patients on the aims of the study, its protocol, possible complications, and the importance of such survey. An informed written consent was obtained from the subjects willing to participate.

\section{Treatment customization and planning}

After initial examinations, the physicians had to draw the treatment region of interest (ROI) on the skin surface. The ROI was the visible tumor plus a 1 to $2 \mathrm{~cm}$ radial margin. For the adjuvant cases, surgical bed with zero to one $\mathrm{cm}$ margin depending on the status of surgical margins formed the ROI. This drawing represented the mold periphery. Alginate was used for creating the mold. After mold formation, a piece of metal wire was placed at the edges. The catheters were implanted in the mold. The number of catheters and their distribution was determined based on the size of the tumor/tumor bed and its location. The catheters were placed with $1 \mathrm{~cm}$-space from each other in a single plane. Plastic tube applicators (French 5) were used for afterloading of radioactive sources. Computed tomography (CT) simulation with $1 \mathrm{~mm}$ thickness slices was made for planning with the mold in place. Clinical target volume was drawn in the Flexiplan software version 2.6 (Isodosecontrol BV., Veenendaal, The Netherlands) according to the metal wire visible in images. The depth of the desired CTV was based on imaging findings (simulation CT or pre-treatment magnetic resonance imaging $[\mathrm{MRI}])$. The maximum allowed depth was $10 \mathrm{~mm}$ from the skin surface. Paris system dosimetry was used for planning. A radiation oncologist controlled the treatment plan concerning $\mathrm{D}_{90}$ (the dose that $90 \%$ of the target volume receives), $\mathrm{V}_{100}$ (the volume receiving $100 \%$ of the prescribed dose), and conformity index ( $\geq 70 \%$ was considered acceptable). Flexitron (Elekta) machine was used for afterloading the radionuclide sources $\left({ }^{192} \mathrm{Ir}\right)$ to the treatment positions. Figure 1 shows a finalized three-dimensional plan in one of our patients with scalp BCC who underwent adjuvant radiotherapy due to positive surgical margin.

\section{Follow-up}

Patients were followed for 2 years after treatment. Based on the guidelines of Radiation Therapy Oncology Group (RTOG) and the European Organization for Research and Treatment of Cancer (EORTC) [15], acute toxicity (erythema and wet desquamation) was evaluated through examination at day one, 1, and 3 months after the treatment. Similarly, the patients were examined after 6 months, 1 year, and 2 years post-treatment for an incident of late toxicity (atrophy and pigmentation). The patients were also evaluated for response to treatment, cosmetic results, and signs of recurrence. Examination and observations were completed by two radiation oncologists. Suspected recurrences were confirmed by punch biopsy and pathologic review.

\section{Outcome measures}

The primary outcomes in this study were acute and late complications. The secondary outcomes included response 

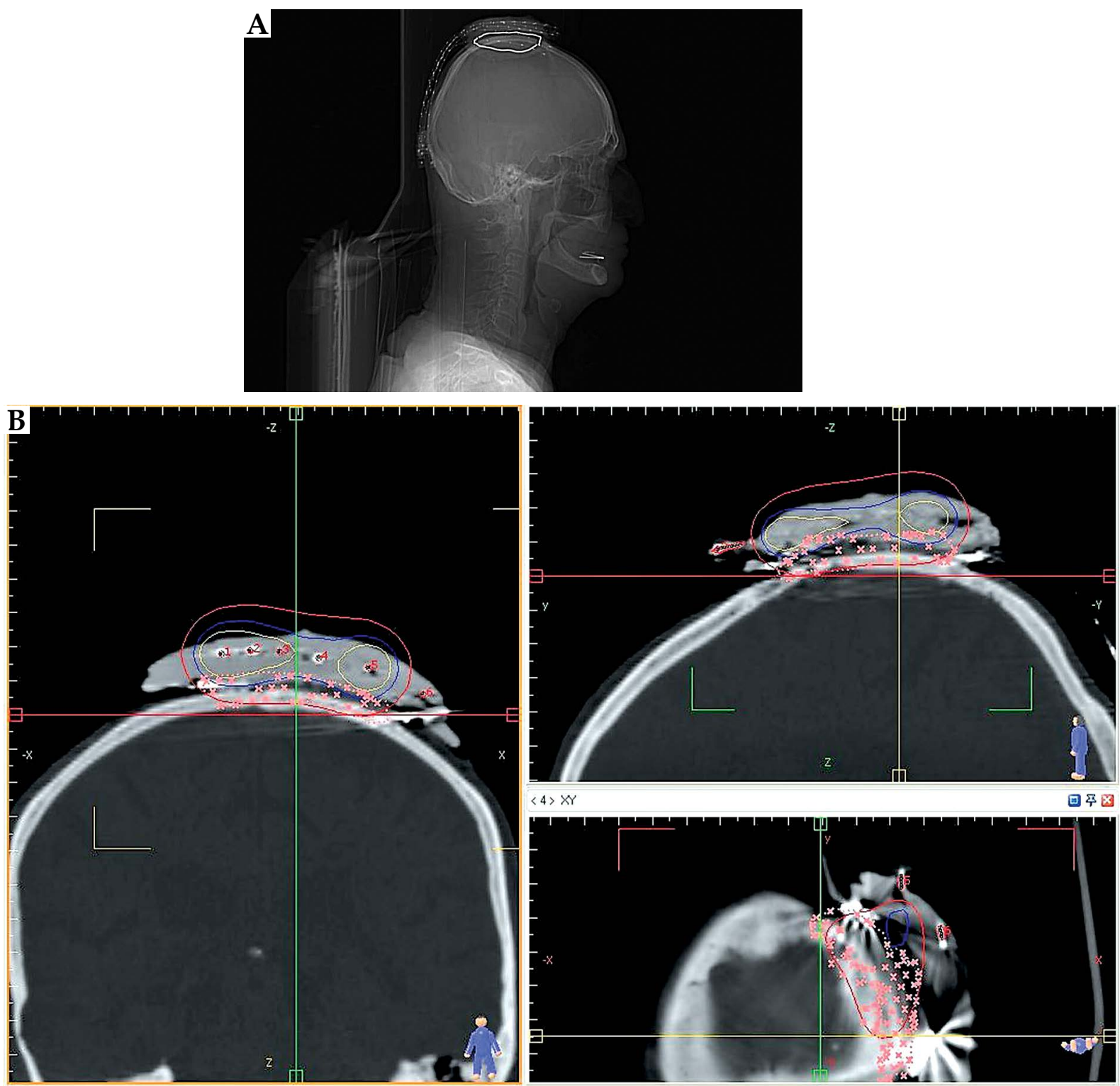

Fig. 1. A) The digital reconstruction radiograph of a patient with scalp basal cell carcinoma. The picture shows the surface mold placed over the scalp encompassing after-loading catheters. B) The dose distribution of the finalized 3D plan in axial, sagittal, and coronal planes. The yellow, blue, and the red lines represent $\mathrm{D}_{200}, \mathrm{D}_{150}$, and $\mathrm{D}_{100}$, respectively. The tiny crosses show the planning target volume

to treatment, local control, and overall survival and cosmetic results. Overall survival was defined as the fraction of patients who survived after the end of radiotherapy to the end of the first or second year of follow-up. Local control rate was defined as the percentage of patients without persistent/residual lesions or recurrence in the same site one or two years after the treatment. The cosmetic results were assessed by two physicians based on the tool that was developed by authors (Table 1). We defined two cosmetics groups for simplicity and less inter-observer bias.

\section{Statistical analysis}

The patients were subdivided into two groups including definitive and adjuvant radiotherapy for comparison.
Table 1. The tool for the assessment of the cosmetic results by the physician

\begin{tabular}{|c|c|}
\hline $\begin{array}{l}\text { Cosmetic assess- } \\
\text { ment group }\end{array}$ & Items \\
\hline \multirow{3}{*}{$\begin{array}{l}\text { Good/excellent } \\
\text { (all of the items) }\end{array}$} & No to mild telangiectasia \\
\hline & No to mild fibrosis \\
\hline & $\begin{array}{l}\text { No to mild hypo- } \\
\text { or hyper-pigmentation }\end{array}$ \\
\hline \multirow{3}{*}{$\begin{array}{l}\text { Bad (either } \\
\text { of the items) }\end{array}$} & Moderate to severe fibrosis \\
\hline & Skin contracture \\
\hline & $\begin{array}{c}\text { Moderate to severe hypo- } \\
\text { or hyper-pigmentation }\end{array}$ \\
\hline
\end{tabular}


$\chi^{2}$ test was used to compare the rate of treatment-related toxicity between groups. Kaplan-Meier method was applied for estimation of actuarial survival rate and curves. We used log-rank test to compare survival rates between groups. Actuarial rates of overall survival and local failure were calculated based on the time interval from the last radiotherapy session to the last uneventful follow-up, or all-cause mortality and the date of failure, respectively. SPSS software version 22 (IBM Corp., Chicago, IL, USA) was used for all analyses. The level of significance for all statistical tests was placed at 0.05. Timeevent rates were presented with confidence interval 95\% (CI 95\%).

\section{Results}

\section{Patients and tumors characteristics}

A total of 60 patients were recruited for the study. Male to female ratio was $40: 20$, and the BCC to SCC ratio was $45: 15$. The median age was 71 years, ranging from 37 to 100 years. The most and least frequent sites of involvement were scalp (33\%) and eyelid (3\%), respectively. The median tumor size and thickness were $3 \mathrm{~cm}$ (range, 0.5-12) and $0.5 \mathrm{~cm}$ (range, 0.1-1), respectively.
The intention of brachytherapy was definitive in 42 patients $(70 \%)$ and adjuvant in the remaining. As presented in Table 2, there was no significant difference between the two groups of definitive and adjuvant treatment in terms of gender, age, the situation of the tumor, or pathology of lesion.

\section{Dose and planning characteristics}

The characteristics of prescribed total dose, dose per fractions and $D_{90}$ and $V_{100}$ are presented in Table 2 . The median dose/fraction was $3 \mathrm{~Gy}$ in the definitive, and 4 Gy in the adjuvant setting. The range of total physical dose was between 30 and $52 \mathrm{~Gy}$. This dose was prescribed in a minimum of 10 and a maximum of 13 fractions. The median $\mathrm{EQD}_{2}$ was 42.2 Gy (range, 33-61), $42.2 \mathrm{~Gy}$, and $54.4 \mathrm{~Gy}$ in all, definitive, and adjuvant groups, respectively. The median $\mathrm{V}_{100}$ was $14.5 \mathrm{ml}$ (range, 2.6-152.8) and $38.5 \mathrm{ml}$ (range, 4.9-129.5) in the definitive and adjuvant settings, respectively.

As evident in Table 2, no significant difference was observed between the two groups of definitive and adjuvant in quantitative treatment parameters measured, except for total EQD2 dose that was higher in the adjuvant setting.

Table 2. General characteristics of the patients and the treatment parameters

\begin{tabular}{|c|c|c|c|c|c|}
\hline \multicolumn{2}{|c|}{ Qualitative variables } & \multirow{3}{*}{$\begin{array}{l}\text { Total frequency (\%) } \\
20(33.3)\end{array}$} & \multicolumn{2}{|c|}{ Group } & \multirow[t]{2}{*}{$p$ value } \\
\hline & & & Definitive frequency (\%) & Adjuvant frequency (\%) & \\
\hline \multirow[t]{2}{*}{ Gender } & Female & & $14(33.3)$ & $6(33.3)$ & 1.000 \\
\hline & Male & $40(66.7)$ & $28(66.7)$ & $12(66.7)$ & \\
\hline \multirow[t]{2}{*}{ Age group } & $\leq 70$ & $29(48.3)$ & $20(47.6)$ & $9(50.0)$ & 0.866 \\
\hline & $>70$ & $31(51.7)$ & $22(52.4)$ & $9(50.0)$ & \\
\hline \multirow[t]{5}{*}{ Location } & Face & $19(31.7)$ & $11(26.2)$ & $8(44.4)$ & 0.132 \\
\hline & Scalp & $20(33.3)$ & $13(31.0)$ & $7(38.9)$ & \\
\hline & Nose & $15(25.0)$ & $14(33.3)$ & $1(5.6)$ & \\
\hline & Ear & $4(6.7)$ & $2(4.8)$ & $2(11.1)$ & \\
\hline & Eyelid & $2(3.3)$ & $2(4.8)$ & $0(0.0)$ & \\
\hline \multirow[t]{2}{*}{ Pathology } & $\mathrm{BCC}$ & $45(75.0)$ & $33(78.6)$ & $12(66.7)$ & 0.347 \\
\hline & SCC & $15(25.0)$ & $9(21.4)$ & $6(33.3)$ & \\
\hline \multicolumn{2}{|c|}{ Quantitative variables } & $\begin{array}{l}\text { Total mean } \\
\text { (std. dev.) }\end{array}$ & $\begin{array}{c}\text { Definitive mean } \\
\text { (std. dev.) }\end{array}$ & $\begin{array}{l}\text { Adjuvant mean } \\
\text { (std. dev.) }\end{array}$ & $p$ value \\
\hline \multicolumn{2}{|c|}{ Duration (days) } & $15.8(4.2)$ & $16.0(4.1)$ & $15.4(4.3)$ & 0.646 \\
\hline \multicolumn{2}{|c|}{ Total dose (Gy) } & $39.6(5.4)$ & $38.8(5.4)$ & $41.5(4.9)$ & 0.064 \\
\hline \multicolumn{2}{|c|}{ Total dose $\mathrm{EQD}_{2}$ (Gy) } & $44.9(7.7)$ & $42.9(6.7)$ & $49.6(8.2)$ & 0.002 \\
\hline \multicolumn{2}{|c|}{ Number of fractions } & $11(1.4)$ & $11(1)$ & $11(1)$ & 0.728 \\
\hline \multicolumn{2}{|c|}{ Dose per fraction (Gy) } & $3.6(0.6)$ & $3.5(0.6)$ & $3.8(0.7)$ & 0.228 \\
\hline \multicolumn{2}{|l|}{$D_{90}(G y)$} & $3.6(0.7)$ & $3.5(0.7)$ & $3.8(0.7)$ & 0.170 \\
\hline \multicolumn{2}{|l|}{$V_{100}\left(\mathrm{~cm}^{3}\right)$} & $34.9(35.5)$ & $29.7(34.8)$ & $47.1(35.1)$ & 0.088 \\
\hline
\end{tabular}

$B C C$ - basal cell carcinoma, $S C C$ - squamous cell carcinoma, $E Q D_{2}(G y)$ - equivalent dose at $2 G y, D_{90}(G y)$ - the minimum dose received by $90 \%$ of the target volume, $V_{100}\left(\mathrm{~cm}^{3}\right)$ - the percentage of the target volume receiving $100 \%$ of the prescribed dose or more 


\section{Post-treatment complications}

\section{Acute toxicity}

One day after treatment, 26 patients $(43.3 \%)$ had grade 1-2, and 31 (51.7\%) experienced grade 3-4 acute toxicity. Although the rate of grade 3-4 toxicities among the patients who underwent brachytherapy as definitive treatment was higher than the adjuvant group, the differences were not statistically significant. One month after treatment, $25 \%$ of patients were found to have grade 3-4 toxicities. By the end of third month, this figure decreased to $6.7 \%$. Similarly, the rates of toxicities were higher in the definitive group, although the differences were nonsignificant (Table 2).

\section{Late toxicity}

Patients were assessed for the late toxicities at 6 months, one year, and two years post-treatment. More than half of patients $(50.8 \%)$ had signs of late grade $1-2$ toxicity at 6 months follow-up, which decreased to $43.1 \%$ after 1 year. Nevertheless, only one patient showed signs of grade 3-4 toxicity, which was resolved by the $2^{\text {nd }}$ year of follow-up. Thus, the rate of late grade 3-4 toxicity was $1.6 \%, 1.6 \%$, and $0 \%$ at $6^{\text {th }}$ month, $1^{\text {st }}$ year, and $2^{\text {nd }}$ year of follow-up, respectively. Definitive and adjuvant groups were not significantly different from each other considering the rate and grade of late toxicities (Table 3).

\section{Clinical outcomes}

\section{Cosmetic results}

By the end of the first year, out of 58 live patients, $55(94.8 \%)$ were found to have a good/excellent cosmetic outcome. Accordingly, this rate was found to be $92.7 \%$ in the definitive group and $100 \%$ in the adjuvant group. By the end of $2^{\text {nd }}$ year of follow-up, the percentage of good/excellent cosmetic outcome increased to $96.2 \%$ in 52 individuals, $94.4 \%$ in definitive, and $100 \%$ in adjuvant group $(p=0.961)$.

\section{Response to treatment}

Among patients in the definitive group after 1 month, the disease was stable in only 1 patient $(2.4 \%)$, two pa-

Table 3. Acute and chronic toxicities and cosmetic results of the treatment

\begin{tabular}{|c|c|c|c|c|c|c|}
\hline & & & \multirow{2}{*}{$\begin{array}{l}\text { Total frequency } \\
\text { (\%) }\end{array}$} & \multicolumn{2}{|c|}{ Group } & \multirow[t]{2}{*}{$p$ value } \\
\hline & & & & $\begin{array}{c}\text { Definitive } \\
\text { frequency (\%) }\end{array}$ & $\begin{array}{c}\text { Adjuvant } \\
\text { frequency (\%) }\end{array}$ & \\
\hline \multirow[t]{9}{*}{ Acute toxicity } & \multirow[t]{3}{*}{ One day after treatment } & No toxicity & $3(5.0)$ & $1(2.4)$ & $2(11.1)$ & \multirow[t]{3}{*}{0.358} \\
\hline & & Grade $1-2$ & $26(43.3)$ & $19(45.2)$ & $7(38.9)$ & \\
\hline & & Grade 3-4 & $31(51.7)$ & $22(52.4)$ & $9(50.0)$ & \\
\hline & \multirow[t]{3}{*}{1 month after treatment } & No toxicity & $23(38.3)$ & $17(40.5)$ & $6(33.3)$ & \multirow[t]{3}{*}{0.869} \\
\hline & & Grade 1-2 & $22(36.7)$ & $15(35.7)$ & $7(38.9)$ & \\
\hline & & Grade 3-4 & $15(25.0)$ & $10(23.8)$ & $5(27.8)$ & \\
\hline & \multirow[t]{3}{*}{3 months after treatment } & No toxicity & $44(73.3)$ & $30(71.4)$ & $14(77.8)$ & \multirow[t]{3}{*}{0.397} \\
\hline & & Grade $1-2$ & $12(20.0)$ & $10(23.8)$ & $2(11.1)$ & \\
\hline & & Grade 3-4 & $4(6.7)$ & $2(4.8)$ & $2(11.1)$ & \\
\hline \multirow[t]{9}{*}{ Late toxicity } & \multirow[t]{3}{*}{6 months after treatment } & No toxicity & $29(49.2)$ & $18(43.9)$ & $11(61.1)$ & \multirow[t]{3}{*}{0.417} \\
\hline & & Grade $1-2$ & $29(49.2)$ & $22(53.7)$ & $7(38.9)$ & \\
\hline & & Grade 3-4 & $1(1.7)$ & $1(2.4)$ & $0(0.0)$ & \\
\hline & \multirow[t]{3}{*}{1 year after treatment } & No toxicity & $33(56.9)$ & $21(51.2)$ & $12(70.6)$ & \multirow[t]{3}{*}{0.361} \\
\hline & & Grade 1-2 & $24(41.4)$ & $19(46.3)$ & $5(29.4)$ & \\
\hline & & Grade 3-4 & $1(1.7)$ & $1(2.4)$ & $0(0.0)$ & \\
\hline & \multirow[t]{3}{*}{2 years after treatment } & No toxicity & 27 (51.9) & $16(44.4)$ & $11(68.8)$ & \multirow[t]{3}{*}{0.138} \\
\hline & & Grade $1-2$ & $25(48.1)$ & $20(55.6)$ & $5(31.3)$ & \\
\hline & & Grade 3-4 & $0(0.0)$ & $0(0.0)$ & $0(0.0)$ & \\
\hline \multirow{4}{*}{$\begin{array}{l}\text { Cosmetic } \\
\text { results }\end{array}$} & \multirow[t]{2}{*}{ After 1 year } & Bad & $3(5.2)$ & $3(7.3)$ & $0(0.0)$ & \multirow[t]{2}{*}{0.548} \\
\hline & & Good & $55(94.8)$ & 38 (92.7) & 17 (100.0) & \\
\hline & \multirow[t]{2}{*}{ After 2 years } & Bad & $2(3.8)$ & $2(5.6)$ & $0(0.0)$ & \multirow[t]{2}{*}{0.336} \\
\hline & & Good & $50(96.2)$ & $34(94.4)$ & $16(100.0)$ & \\
\hline
\end{tabular}




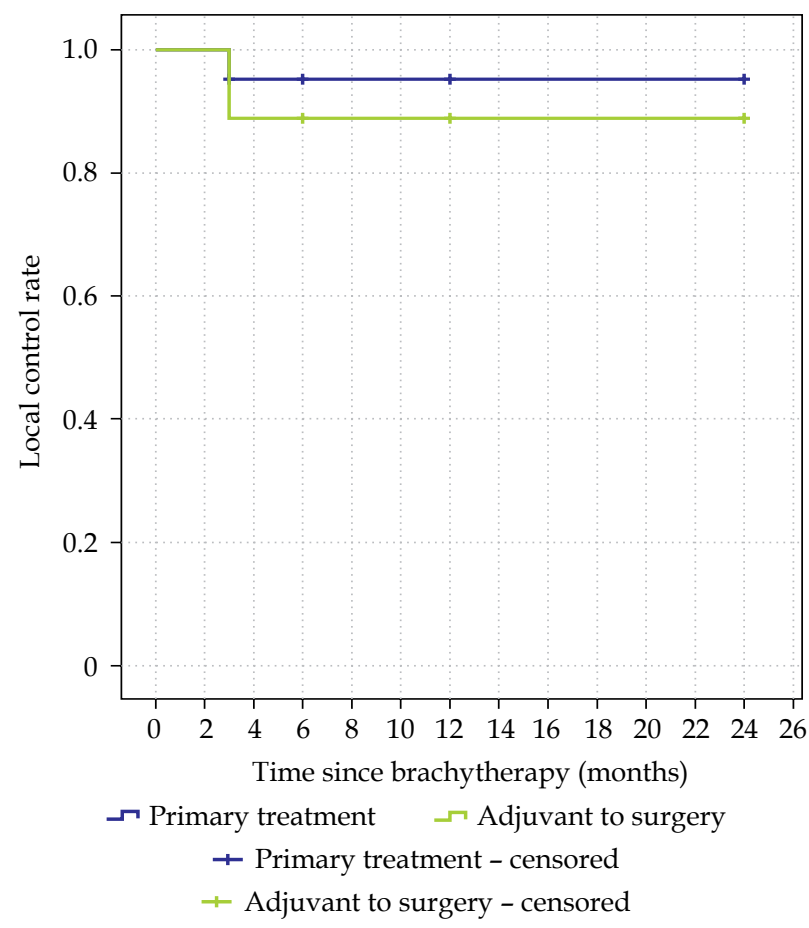

Fig. 2. The Kaplan-Meyer graph for actuarial local control. The blue and green lines represent definitive and adjuvant treatments, respectively tients $(4.8 \%)$ showed partial response, and remaining $92.9 \%$ had a complete response to the treatment. By the $3^{\text {rd }}$ month, one of the partial responders was converted to complete, comprising 40 patients $(95.2 \%)$ with complete response, $1(2.4 \%)$ with partial response, and $1(2.4 \%)$ with stable disease. The rate of clinical response was not associated with total dose or dose/fraction.

\section{Local control}

The lesions recurred in $2 / 18$ patients $(11.1 \%)$ who underwent adjuvant treatment. The recurrences were treated by surgical excision. Among patients undergoing definitive therapy, $2 / 42(4.7 \%)$ experienced local failure after 3 months. In both groups, no other recurrences occurred until the end of 2 years follow-up. As depicted in Figure 2, the 2-year actuarial local control rate was calculated to be $95 \%$ (CI 95\%: 89-100) in the definitive group, and $88 \%$ (CI 95\%: 74-100) in the adjuvant group.

\section{Overall survival}

Median follow-up time was 2 years (range, 3-24 months). During this time, six persons died ( 1 by 6 months, 2 by the first year). Only one of these patients who underwent definitive HDR-BT for scalp lesion deceased because of their disease (after recurrence), and the other five died due to other causes than the malignancy. The 2-year overall

Table 4. Effect of dosimetric parameters on outcomes

\begin{tabular}{|c|c|c|c|c|c|c|}
\hline \multirow{2}{*}{$\begin{array}{l}\text { Setting } \\
\text { Definitive }\end{array}$} & \multicolumn{2}{|c|}{ Dosimetric parameter } & \multirow{2}{*}{$\begin{array}{c}\begin{array}{c}\text { Grade } 2-4 \text { acute } \\
\text { toxicity }\end{array} \\
18(85.7)\end{array}$} & \multirow{2}{*}{$\begin{array}{c}\begin{array}{c}\text { Grade } 2-4 \text { late } \\
\text { toxicity }\end{array} \\
1(4.8)\end{array}$} & \multirow{2}{*}{$\begin{array}{c}\text { Bad cosmetic } \\
\text { results }\end{array}$} & \multirow{2}{*}{$\begin{array}{c}\text { Local failure } \\
0(0)\end{array}$} \\
\hline & Dose/fraction & $\leq 3 \mathrm{~Gy}$ & & & & \\
\hline & & $>3 \mathrm{~Gy}$ & $19(90.5)$ & $5(25)$ & $2(10)$ & $2(9.5)$ \\
\hline & & $p$ value & 0.99 & 0.09 & 0.60 & 0.49 \\
\hline & Total dose $\mathrm{EQD}_{2}$ & $\leq 42.25$ Gy & $27(84.4)$ & $5(15.6)$ & $3(9.4)$ & $2(6.2)$ \\
\hline & & $>42.25 \mathrm{~Gy}$ & $10(100)$ & $1(11.1)$ & $0(0)$ & $0(0)$ \\
\hline & & $p$ value & 0.31 & 0.99 & 0.99 & 0.99 \\
\hline & $V_{100}$ & $\leq 15$ & $17(81)$ & $0(0)$ & $0(0)$ & $0(0)$ \\
\hline & & $>15$ & $20(95.2)$ & $6(30)$ & $3(15)$ & $2(9.7)$ \\
\hline & & $p$ value & 0.34 & 0.01 & 0.11 & 0.49 \\
\hline \multirow[t]{9}{*}{ Adjuvant } & Dose/fraction & $\leq 3.5 \mathrm{~Gy}$ & $6(66.7)$ & $1(10)$ & $0(0)$ & $0(0)$ \\
\hline & & $>3.5 \mathrm{~Gy}$ & $6(75)$ & $1(12.5)$ & $0(0)$ & $2(25)$ \\
\hline & & $p$ value & 0.99 & 0.99 & 0.99 & 0.18 \\
\hline & Total dose $\mathrm{EQD}_{2}$ & $\leq 46.67 \mathrm{~Gy}$ & $5(55.6)$ & $2(22.2)$ & $0(0)$ & $0(0)$ \\
\hline & & $>46.67 \mathrm{~Gy}$ & $7(87.5)$ & $0(0)$ & $0(0)$ & $2(22.2)$ \\
\hline & & $p$ value & 0.29 & 0.47 & 0.99 & 0.47 \\
\hline & $V_{100}$ & $\leq 38.5$ & $4(50)$ & $0(0)$ & $0(0)$ & $0(0)$ \\
\hline & & $>38.5$ & 8 (88.9) & $2(22.2)$ & $0(0)$ & $2(22.2)$ \\
\hline & & $p$ value & 0.13 & 0.47 & 0.99 & 0.47 \\
\hline
\end{tabular}

EQD2 (Gy) - equivalent dose at $2 \mathrm{~Gy}, V_{100}\left(\mathrm{~cm}^{3}\right)$ - the percentage of the target volume receiving $100 \%$ of the prescribed dose or more 
Table 5. Characteristics of patients with local failures

\begin{tabular}{lccccccccccccccc} 
& Setting & $\begin{array}{c}\text { Time of } \\
\text { evaluation }\end{array}$ & $\begin{array}{c}\text { Physical } \\
\text { Dose/no of } \\
\text { fractions }\end{array}$ & $\begin{array}{c}\text { Dose/ } \\
\text { fraction }\end{array}$ & $\mathrm{EQD}_{2}$ & $\begin{array}{c}\mathrm{V}_{100} \\
(\mathrm{ml})\end{array}$ & $\begin{array}{c}\text { Histologic } \\
\text { type }\end{array}$ & Location & Age & Gender \\
\hline $1^{\text {st }}$ Patient & Definitive & 3 months & $45 / 10$ & 4.5 & 42.25 & 152.8 & BCC & Scalp & Male \\
\hline $2^{\text {nd }}$ Patient & Definitive & 3 months & $48 / 12$ & 4 & 39.38 & 64 & BCC & Scalp & Male \\
\hline $3^{\text {rd }}$ Patient & Adjuvant & 3 months & $45 / 10$ & 4.5 & 54.38 & 53.6 & BCC & Scalp & 50 & Female \\
\hline $4^{\text {th }}$ Patient & Adjuvant & 3 months & $45 / 10$ & 4.5 & 54.38 & 53.6 & BCC & Face & 50 & Female
\end{tabular}

$E Q D_{2}(G y)$ - equivalent dose at $2 \mathrm{~Gy}, V_{100}\left(\mathrm{~cm}^{3}\right)$ - the percentage of the target volume receiving $100 \%$ of the prescribed dose or more, BCC - basal cell carcinoma

survival (OS) rate was $87 \%, 86 \%$, and $89 \%$ in total, definitive, and adjuvant groups, respectively.

\section{Effect of dosimetric parameters on outcomes}

As shown in Table 4 and 5, among patients undergoing definitive brachytherapy, higher dose per fraction and $V_{100}$ were associated with a trend toward a higher frequency of grade 2 or greater late toxicities, with $p$ values less than 0.1 and 0.01 , respectively. After multivariate analysis, only $\mathrm{V}_{100}>15 \mathrm{ml}$ was independent predictor of late toxicity in definitive cases. Otherwise, in both univariate and multivariate analyses, there were no significant associations among the parameters, and late toxicity, acute toxicity, cosmetic results, and local failure in either definitive or adjuvant settings.

\section{Discussion}

The outcome and cosmetic results of HDR-BT along with its associated acute and late toxicity were assessed in this prospective study conducted on patients with NMSC. The age distribution of our patients was the same in the adjuvant and definitive groups. One could presume that patients in the adjuvant groups should be significantly younger. This presumption roots in the potential risk of radiation-induced second neoplasms. The reason is that the standard Mohs's surgery is not routinely carried out in most parts of Iran. At present, extensive surgical excisions to achieve wide negative margins are not associated with good cosmetic results, especially in the face. Thus, many of the young patients preferred radiation therapy over surgery accepting the risk of secondary malignancies. There was a relative wide dose range in our study. In the beginning, we used bigger dose per fractions of 4-4.5 Gy and higher total dose of about $52 \mathrm{~Gy}$. But, gradually, by observing some acute complications we lowered the dose/fractions and total dose to uniform 39 Gy in 13 daily fractions five days a week. This is the explanation for our dose range. The $D_{90}$ should receive the prescribed dose. Our initial patients received adjuvant radiotherapy and by the compilation of the experiences, we started definitive treatment. Therefore, the total $\mathrm{EQD}_{2}$ dose was significantly higher in the adjuvant group. Besides, our adjuvant cases were all patients with microscopic or macroscopic residue after surgery who were not amenable to further resections and had a high chance of progression without adjuvant treatments. We added that results of the analysis of the link between dosimetric parameters including dose/fraction, total dose, and $\mathrm{V}_{100}$ with toxicities. Interestingly, we found that post-treatment/fraction over 3 Gy was associated with higher late toxicity in the definitive setting. Thus, this is a possible explanation for our high toxicity rates. Also, the mean depth of the lesions studied was more elevated than similar investigations. When treating deep-seated tumors, the superficial skin places in $\mathrm{D}_{100}$ or $\mathrm{D}_{150}$ and consequently, receives higher doses than the most in-depth segment. This non-uniformity (over 3\%) could be another explanation for our higher toxicities compared to the literature [16].

In similar studies reporting the results of HDR-BT treatment with surface molds, the range of local control varied between $87 \%$ to $100 \%$ [17,18,19,20]. Considering CI 95\%, our 2-year local control was in agreement with other studies. Although, several factors have been proposed for differences observed in local control rates; these include tumor size (small vs. large), location (plain vs. curved surfaces), treatment margin, and histology (BCC vs. SCC). In our study, the majority of recurrent cases were large lesions on the scalp with BCC histology. Our small sample size limited the potential to compare the effect of these factors on local control. Nevertheless, there was no statistically significant difference between definitive and adjuvant treatment groups.

Our cosmetic results with HDR-BT were quite promising, with more than $95 \%$ of cases showing good/excellent results after two years of follow-up. Other studies using HDR-BT or electronic brachytherapy achieved similar results $[8,21,22]$.

HDR-BT was quite tolerable by our patients, with meager rates of severe acute and late toxicities. Theoretically, some investigators believed that large fraction size used with HDR-BT might be associated with higher late toxicity $[19,20,21]$. Although several other investigations counteracted this belief, our study suggested that the lower dose/fraction, the better late toxicity profile. Overall, the results of all the available literature on this subject, including the present study indicates that HDR-BT is associated with good treatment outcomes and acceptable acute and late complications. Therefore, this modality could be considered as a mainstay treatment for NMSCs located on the nose, eyelid, ear, and any other region where surgical excision might be difficult, or the required anesthesia harbors high-risk for patient life. This is particularly the issue in the elderly and frail patients who 
share the most substantial contribution to the prevalence of skin cancers [23].

\section{Conclusions}

As long as the dose/fraction is kept below $3 \mathrm{~Gy} /$ fraction, HDR-BT is an attractive modality to manage skin cancers in the head and neck region with acceptable toxicity and promising cosmetic results. Longer follow-up is needed to establish the long-term local control rates confidently.

\section{Acknowledgments}

We would like to appreciate the staff of brachytherapy ward Mrs. Shaahnazari, Mrs. Machinforoosh, and Mrs. Mahdavi for their valuable co-operation in the treatment of our patients and providing the information we needed for this publication.

\section{Disclosure}

The authors report no conflict of interest.

\section{References}

1. Alam M, Nanda S, Mittal BB et al. The use of brachytherapy in the treatment of nonmelanoma skin cancer: a review. J Amer Acad Dermatol 2011; 65: 377-888.

2. Razi S, Rafiemanesh H, Ghoncheh M i wsp. Changing Trends of Types of Skin Cancer in Iran. Asian Pac J Cancer Prev 2015; 16: 4955-4958.

3. Katalinic A, Kunze U, Schäfer T. Epidemiology of cutaneous melanoma and non-melanoma skin cancer in Schleswig-Holstein, Germany: incidence, clinical subtypes, tumour stages and localization (epidemiology of skin cancer). Br J Dermatol 2003; 149: 1200-1206.

4. Macfarlane L, Waters A, Evans A et al. Seven years' experience of Mohs micrographic surgery in a UK centre, and development of a UK minimum dataset and audit standards. Clin Exp Dermatol 2013; 38: 262-269.

5. Caresana G, Giardini R. Dermoscopy-guided surgery in basal cell carcinoma. J Eur Acad Dermatol Venereol 2010; 24: 13951399.

6. Chren MM, Torres JS, Stuart SE et al. Recurrence after treatment of nonmelanoma skin cancer: a prospective cohort study. Arch Dermatol 2011; 147: 540-546.

7. Nguyen TH, Ho DQ. Nonmelanoma skin cancer. Curr Treat Options Oncol 2002; 3: 193-203.

8. Bhatnagar A. Nonmelanoma skin cancer treated with electronic brachytherapy: results at 1 year. Brachytherapy 2013; 12: $134-140$.

9. Ouhib Z, Kasper M, Perez Calatayud J et al. Aspects of dosimetry and clinical practice of skin brachytherapy: The American Brachytherapy Society working group report. Brachytherapy 2015; 14: 840-858.

10. Hansen $\mathrm{PB}$, Jensen MS. Late results following radiotherapy of skin cancer. Acta Radiol Ther Phys Biol 1968; 7: 307-319.

11. Fürst C, Lundell M, Holm LE. Radiation therapy of hemangiomas, 1909-1959 A cohort based on 50 years of clinical practice at Radiumhemmet, Stockholm. Acta Oncol 1987; 26: 33-36.

12. Moss WT, Brand WN, Battifora H. Radiation oncology: rationale, technique, results. C.V. Mosby Co., St. Louis 1973.

13. Gunderson LL, Tepper JE, Bogart JA. Clinical Radiation Oncology. Elsevier Health Sciences, 2015.
14. Devlin PM. Brachytherapy: applications and techniques. Springer Publishing Company, 2015.

15. Cox JD, Stetz J, Pajak TF. Toxicity criteria of the radiation therapy oncology group (RTOG) and the European organization for research and treatment of cancer (EORTC). Int J Radiat Oncol Biol Phys 1995; 31: 1341-1346.

16. Skowronek J. Brachytherapy in the treatment of skin cancer: an overview. Postep Derm Alergol 2015; 32: 362-367.

17. Guix B, Finestres F, Tello JI et al. Treatment of skin carcinomas of the face by high-dose-rate brachytherapy and custom-made surface molds. Int J Radiat Oncol Biol Phys 2000; 47: 95-102.

18. Montero Á, Hernanz R, Capuz AB et al. High-dose-rate (HDR) plesiotherapy with custom-made moulds for the treatment of non-melanoma skin cancer. Clin Transl Oncol 2009; 11: 760-764.

19. Maroñas M, Guinot JL, Arribas L et al. Treatment of facial cutaneous carcinoma with high-dose rate contact brachytherapy with customized molds. Brachytherapy 2011; 10: 221-227.

20. Haseltine JM, Parker M, Wernicke AG et al. Clinical comparison of brachytherapy versus hypofractionated external beam radiation versus standard fractionation external beam radiation for non-melanomatous skin cancers. J Contemp Brachytherapy 2016; 8: 191-196.

21. Paravati AJ, Hawkins PG, Martin AN et al. Clinical and cosmetic outcomes in patients treated with high-dose-rate electronic brachytherapy for nonmelanoma skin cancer. Pract Radiat Oncol 2015; 5: e659-664.

22. Delishaj D, Laliscia C, Manfredi B et al. Non-melanoma skin cancer treated with high-dose-rate brachytherapy and Valencia applicator in elderly patients: a retrospective case series. J Contemp Brachytherapy 2015; 7: 437-444.

23. Lancellotta V, Lupattelli M, Zucchetti C et al. HDR Brachytherapy for Basal Cell Carcinoma. J Nucl Med Radiat Ther 2015; 6: 2. 